\title{
Epithelial-mesenchymal transition induced by the stromal cell-derived factor-1/CXCR4 system in oral squamous cell carcinoma cells
}

\author{
TOMITARO ONOUE* , DAISUKE UCHIDA*, NASIMA MILA BEGUM, \\ YOSHIFUMI TOMIZUKA, HIDEO YOSHIDA and MITSUNOBU SATO \\ Second Department of Oral and Maxillofacial Surgery, Tokushima University \\ School of Dentistry, 3-18-15 Kuramoto, Tokushima 770-8504, Japan
}

Received May 11, 2006; Accepted July 12, 2006

\begin{abstract}
Epithelial-mesenchymal transition (EMT) refers to critical events occasionally observed during tumor progression, including invasion and metastasis, by which cancer cells acquire a fibroblast-like phenotype. Since the stromal cellderived factor-1 (SDF-1)/CXCR4 system can facilitate lymph node metastasis in oral squamous cell carcinoma (SCC), we have explored the possibility that this system might be involved in EMT. Oral SCC cells, B88 and HNt, which have functional CXCR4 and lymph node metastatic potential, were found to lose their epithelial cell morphology due to SDF-1. In this context, the downregulation of epithelial markers, cytokeratin, E-cadherin and B-catenin, and the upregulation of mesenchymal marker, vimentin and snail were detected. Furthermore, upregulation of vimentin by treatment with SDF-1 was impaired by phosphatidylinositol 3 kinase (PI3K) inhibitor Wortmannin, but not by mitogenactivated protein kinase/extracellular signal-regulated kinase inhibitor U0126. In the type I collagen embedding culture, SDF-1-treated B88 cells formed protruding extensions, but the effect was impaired by treatment with Wortmannin. These results suggested that EMT induced by the SDF-1/ CXCR4 system might be involved in the lymph node metastasis of oral SCCs via activation of PI3K-Akt/PKB pathway.
\end{abstract}

\section{Introduction}

Chemokines are a large family of small (7-15 kDa) structurally related heparin-binding proteins that have been identified as attractants of different types of blood leukocytes to sites of

Correspondence to: Dr Daisuke Uchida, Second Department of Oral and Maxillofacial Surgery, Tokushima University School of Dentistry, 3-18-15 Kuramoto, Tokushima 770-8504, Japan

E-mail:daisuke@dent.tokushima-u.ac.jp

${ }^{*}$ Contributed equally

Key words: EMT, oral SCC, CXCR4, SDF-1 infection and inflammation $(1,2)$. They are produced locally in the tissues and act on leukocytes through selective membranebound G-protein-coupled receptors, the two major subfamilies of which are designated as CCR and CXCR. Among these chemokines and their receptors, the stromal cell-derived factor-1 (SDF-1), also referred to as the CXCL12)/CXCR4 system, has been demonstrated to be involved in lymph node or distant metastasis of several types of cancer (3-9). We have also reported the involvement of this system in lymph node metastasis associated with oral squamous cell carcinoma (SCC) $(10,11)$. Moreover, we have recently found that the expression of CXCR4 in oral SCC at the primary site was significantly associated with lymph node metastasis, the mode of invasion, tumor recurrence, and patient prognosis (12). On the other hand, recent investigations have suggested that the SDF-1/CXCR4 system is involved not only in metastasis but also in the growth and survival of the cancer cells (13-15), indicating that this system regulates the acquisition of various malignant phenotypes observed in cancer cells.

Epithelial-mesenchymal transition (EMT), i.e. the acquisition of a mesenchymal phenotype by epithelial cells, is known to take place during critical phases of embryonic development, including morphogenesis and tissue remodeling, in many animal species, and this process is characterized by the disassembly of cell-cell contacts, the reorganization of the actin cytoskeleton, and cell-cell separation (16). EMT is also a critical event that is occasionally observed during tumor progression, including invasion and metastasis, by which cancer cells acquire a more aggressive phenotype $(17,18)$. Under these conditions, EMT is defined as the occurrence of a variable proportion of tumor cells that upregulate mesenchymal markers such as vimentin and snail, and that downregulate epithelial markers such as E-cadherin $(17,18)$. The expression of these EMT markers is induced by a number of growth factor/receptor systems such as the hepatocyte growth factor (HGF)/c-met system (19-21) and the transforming growth factor (TGF)- $\beta /$ TGF- $\beta$ receptor system $(22,23)$, both of which are associated with a more aggressive phenotype of cancer cells. However, little information is available regarding the type of EMT induced by chemokine system(s), including the SDF-1/CXCR4 system, despite abundant evidence of the diverse malignant behaviors of such systems in cancer cells. In this study, we investigated 
whether or not the SDF-1/CXCR4 system is associated with EMT in oral SCC cells.

\section{Materials and methods}

Cells and cell culture. B88 and HNt cells (10) were maintained in Dulbecco's modified Eagle's medium (DMEM) supplemented with $10 \%$ fetal calf serum (FCS), $100 \mu \mathrm{g} / \mathrm{ml}$ streptomycin, and $100 \mathrm{U} / \mathrm{ml}$ penicillin in a humidified atmosphere of $95 \%$ air and $5 \% \mathrm{CO}_{2}$ at $37^{\circ} \mathrm{C}$.

Immunocytochemical staining. B88 cells were seeded on the FALCON culture slides (Becton Dickinson Labware, Franklin Lakes, NJ), followed by treatment with or without SDF-1 $\alpha$ (R\&D, Minneapolis, MN) under serum-starved conditions. Cells were fixed with $4 \%$ paraformaldehyde for $10 \mathrm{~min}$ at room temperature $20 \mathrm{~h}$ later. After washing the cells with PBS, non-specific binding was blocked with $1 \%$ BSA in PBS for $1 \mathrm{~h}$ at room temperature. Cells were then incubated with the primary antibodies against vimentin (Dako Corporation, Carpinteria, CA) or E-cadherin (BD Biosciences, Franklin Lakes, NJ). Alexa 594-conjugated anti-mouse antibody (Molecular Probes, Eugene, OR) was used for the detection. After staining with $2 \mu \mathrm{g} / \mathrm{ml}$ 4',6-diamidino-2-phenylindole (DAPI; Roche Molecular Biochemicals, Mannheim, Germany) in PBS for 5 min, slides were mounted with ProLong Antifade (Molecular Probes), and fluorescence signals were observed under a fluorescence microscope (Nikon, Tokyo, Japan).

Quantitative RT-PCR. After stimulation of the cells with or without SDF-1 $\alpha$ under serum-starved conditions, the preparation of total RNA and reverse transcription were performed as described previously (10). E-cadherin, vimentin, snail, matrix metalloproteinase (MMP)-2, MMP-7, urokinase typeplasminogen activator (UPA) and glyceraldehyde 3-phosphate dehydrogenase (GAPDH) mRNA were detected with Taqman ${ }^{\circledR}$ gene expression assay (Applied Biosystems, Foster City, CA), respectively. Gene-specific products were measured continuously by an ABI PRISM 7000 sequence detection system (Applied Biosystems). Experiments were performed three times.

Western blotting. Western blotting was performed as described previously (10). The nitrocellulose membrane (Amersham Pharmacia Biotech, Uppsala, Sweden) was incubated with primary antibodies against vimentin, cytokeratin (Dako Corporation), ß-catenin (BD Biosciences), $\beta$-actin (Sigma, St. Louis, MO) and phosphorylated- or total-ERK1/2 and Akt/PKB (Cell Signaling), followed by horseradish peroxidaseconjugated secondary antibodies. Detection was then performed using an enhanced chemiluminescence kit (Amersham Pharmacia Biotech).

Collagen gel culture. Serum-free three-dimensional cultures of B88 cells were performed as described by Janda et al (22). Cells (in serum-containing medium), rat tail collagen $(3-4 \mathrm{mg} / \mathrm{ml}$ ) (Becton Dickinson) and 10\% GF-reduced Matrigel solution (Becton Dickinson) were mixed rapidly at $0^{\circ} \mathrm{C}$ (final collagen concentration, $1.5 \mathrm{mg} / \mathrm{ml}$ ), and $200 \mu \mathrm{l}$ droplets containing 3,000 cells were dispensed into 24-wells. After solidification
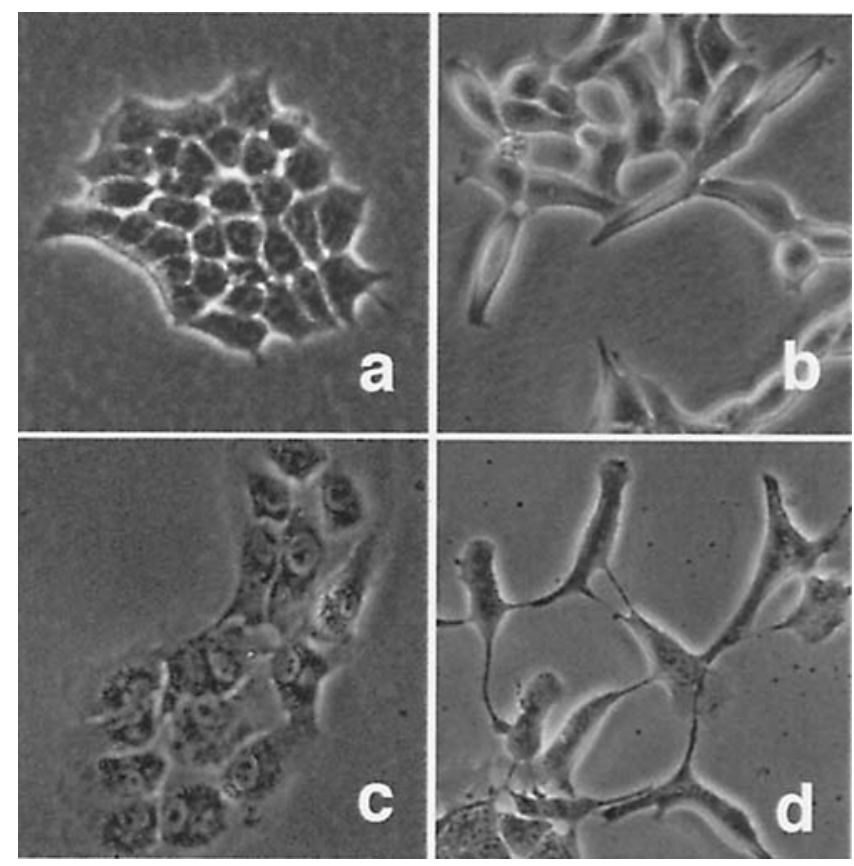

Figure 1. Morphology in SDF-1-treated B88 and HNt cells. B88 and HNt cells were treated with SDF-1 under serum-starved conditions for $72 \mathrm{~h}$. The morphology of the cells was observed under a phase contrast microscope. B88 cells (a) without SDF-1 or (b) with SDF-1. HNt cells (c) without SDF-1 or (d) with SDF-1.

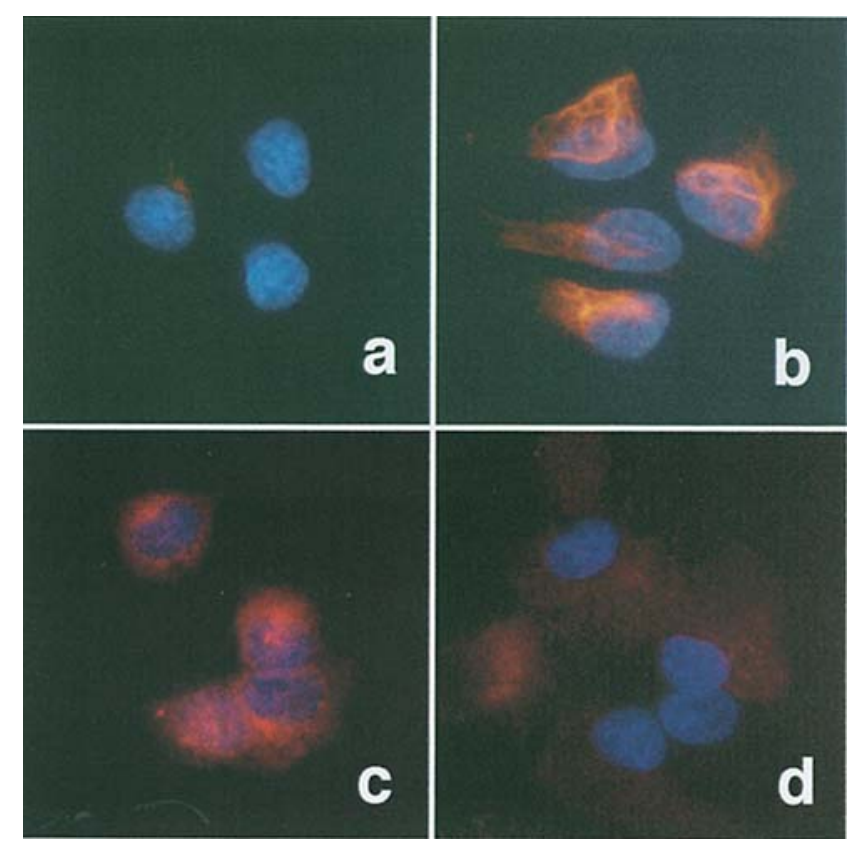

Figure 2. Expression of EMT markers in SDF-1-treated B88 cells. B88 cells were treated with or without SDF-1 under serum-starved conditions. After 72-h incubation, the cells were stained and observed under a fluorescence microscope. Expression of vimentin (red) in B88 cells without SDF-1 (a) or with SDF-1 (b). Expression of E-cadherin (red) in B88 cells without SDF-1 (c) or with SDF-1 (d). The nucleus was stained with DAPI (blue).

on a level surface at room temperature for $30 \mathrm{~min}$, the gels were incubated at $37^{\circ} \mathrm{C}$ in a $\mathrm{CO}_{2}$ incubator for another $1 \mathrm{~h}$ and overlaid with $500 \mu 1$ of serum-free medium. The medium overlaying the gel was changed 1 day after seeding. After 
a

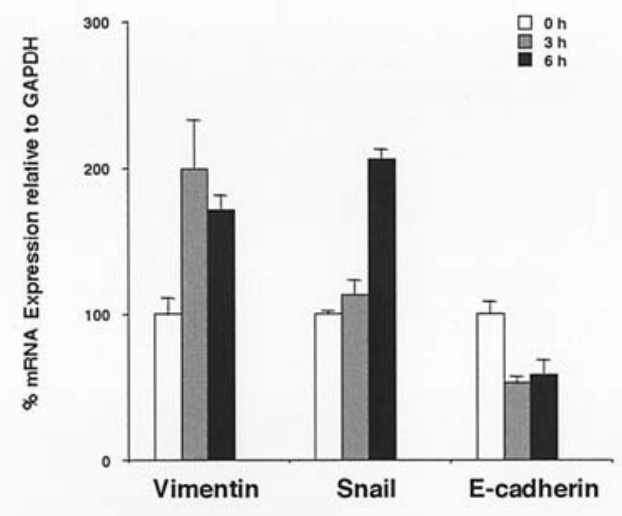

b

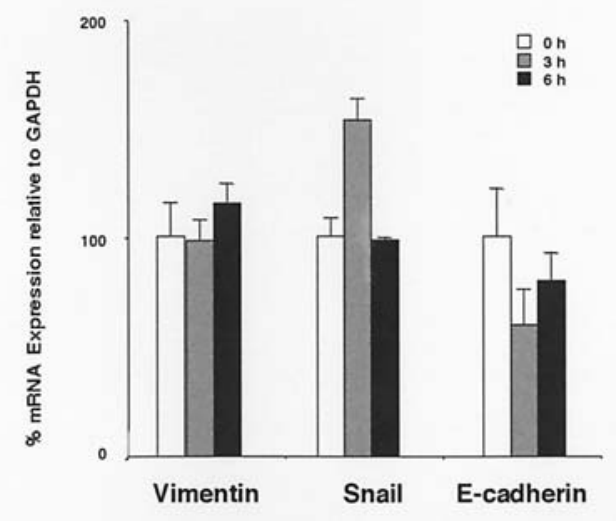

C

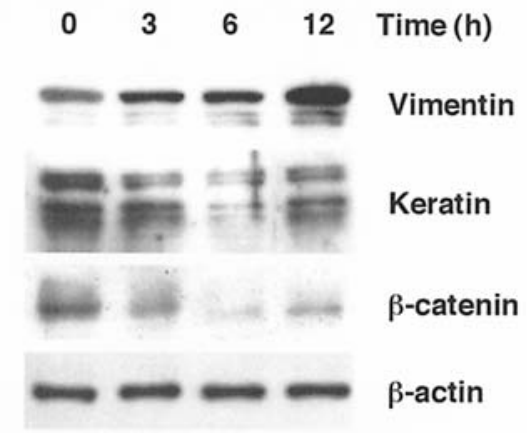

Figure 3. Expression of EMT markers in SDF-1-treated B88 and HNt cells. Expression of EMT marker mRNA (vimentin, snail, E-cadherin) in SDF-1treated B88 cells (a) or HNt cells (b) was examined by quantitative PCR. The bars show the SD of triplicate samples. The data are representative of three separate experiments with similar results. (c) The expression of EMT marker proteins (vimentin, cytokeratin and B-catenin) in SDF-1-treated B88 cells was examined by Western blotting. The data are representative of three separate experiments with similar results.

allowing structure formation of the cells for 4 days, $100 \mathrm{ng} / \mathrm{ml}$ SDF-1 or $5 \mathrm{ng} / \mathrm{ml}$ TGF- $3(\mathrm{R} \& \mathrm{D})$ were added upon medium change every other day, and the cells were further cultivated for 8 days. In some experiments, kinase inhibitor Wortmannin $(50 \mathrm{nM})$ was added every other day.

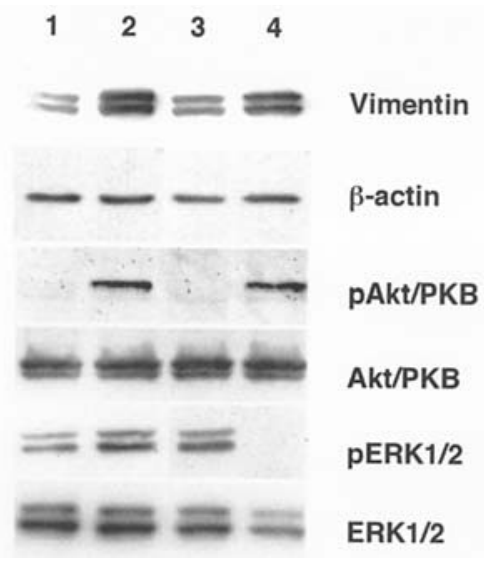

Figure 4. Effect of the kinase inhibitors on the expression of vimentin. Serum-starved B88 cells were incubated with $100 \mathrm{ng} / \mathrm{ml} \mathrm{SDF-1 \alpha}$ for $12 \mathrm{~h}$ with or without $50 \mu \mathrm{M}$ Wortmannin or $10 \mu \mathrm{M}$ U0126, and cell lysates were probed with vimentin antibody. In case of detection of ERK1/2 or Akt/PKB protein, serum-starved B 88 cells were incubated with the same concentration of Wortmannin or U0126 for $45 \mathrm{~min}$ and then stimulated with $100 \mathrm{ng} / \mathrm{ml}$ SDF-1 $\alpha$ for $10 \mathrm{~min}$. Cell lysates were probed with phosphorylated and total ERK1/2 or Akt/PKB Abs.

\section{Results}

Morphological changes induced by the SDF-1/CXCR4 system in B88 and HNt cells. Under conditions of cultivation in complete medium, B88 and HNt cells migrated toward SDF-1 (10), but cell scattering and morphological changes were equivocal. However, when cultivated under serum-starved conditions, some cells began to scatter after 48-h treatment with SDF-1 (12); most of the B88 cells (Fig. 1a and b) and $30 \%$ of the HNt cells (Fig. 1c and d) switched their morphology to fibroblast-like phenotype at $72 \mathrm{~h}$. The morphological change effectively occurred in the low confluence of the cells.

Expression of EMT markers induced by the SDF-1/CXCR4 system in B88 and HNt cells. Under serum-starved conditions, SDF-1 was found to upregulate the mesenchymal marker, vimentin (Fig. 2a and b), but downregulate the epithelial marker, E-cadherin (Fig. 2c and d). Quantitative RT-PCR analysis revealed that SDF-1 downregulated E-cadherin mRNA, and upregulated the mesenchymal marker, vimentin as well as snail mRNA in B88 cells (Fig. 3a). The change of these EMT markers in HNt cells treated with SDF-1 was similar, but was slight (Fig. 3b). The expression of MMP-2, MMP-7 and uPA were not altered by treatment with SDF-1 in $\mathrm{B} 88$ cells (data not shown). At the protein level, the downregulation of cytokeratin and $B$-catenin was observed, as was the upregulation of vimentin (Fig. 3c). We observed similar changes of EMT proteins in the HNt cells (data not shown).

Effect of the kinase inhibitors on the expression of vimentin. In our previous study, B88 cells migrated toward SDF-1 $\alpha$ via activation of both ERK1/2 and Akt/PKB signaling pathways (10). To study the contribution of these kinases, we examined the effect of an MEK inhibitor, U0126, or a PI3K inhibitor, Wortmannin, on the expression of vimentin induced by SDF-1. Although ERK1/2 and Akt/PKB were rapidly activated by SDF-1 $\alpha$, the activation was completely blocked by treatment with each kinase inhibitor (Fig. 4). Moreover, upregulation 
day 3

day 6

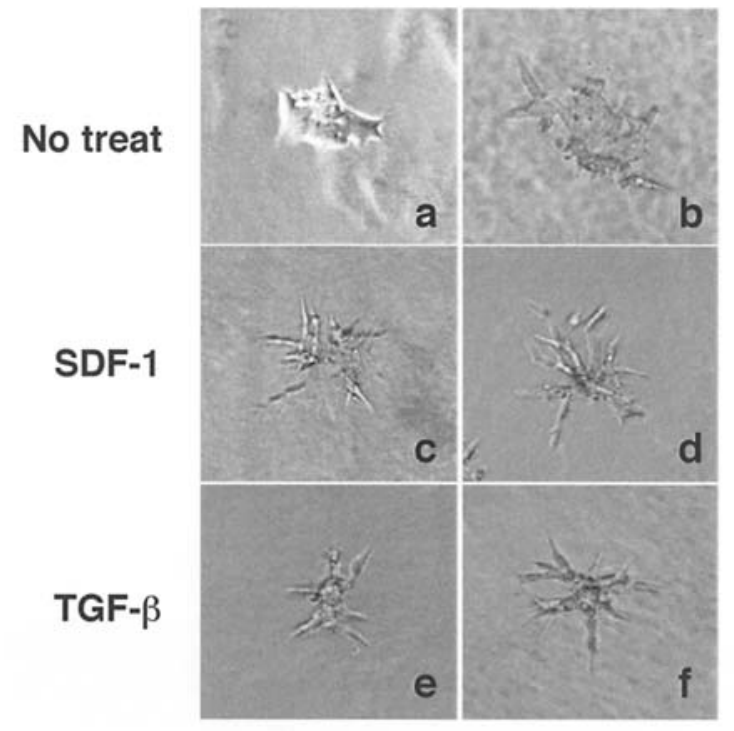

Wort.

SDF-1

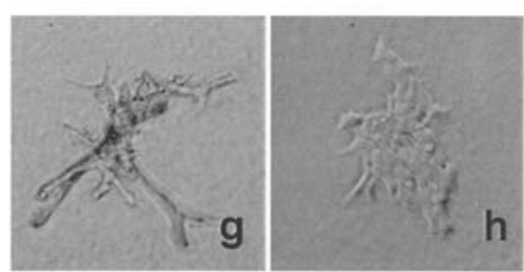

Figure 5. SDF-1 induced EMT in the collagen gel. B88 cells were embedded in rat tail collagen and 10\% GF-reduced Matrigel solution. After allowing structure formation of the cells for 4 days, $100 \mathrm{ng} / \mathrm{ml} \mathrm{SDF}-1$ (c and d) or $5 \mathrm{ng} / \mathrm{ml}$ TGF- $\beta$ (e and $\mathrm{f}$ ) were added for a further 3 or 6 days. SDF-1-treated cells were incubated $(\mathrm{g})$ without or $(\mathrm{h})$ with kinase inhibitor Wortmannin (wort.) for 6 days.

of the vimentin protein was inhibited by treatment with Wortmannin, but not by U0126 (Fig. 4). In the collagen embedding culture of $\mathrm{B} 88$ cells, SDF-1 induced the production of protruding extensions that invade the basement membrane gel, as did TGF- $\beta$. However, the protrusion of B 88 cells by SDF-1 was impaired by the use of Wortmannin, indicating that PI3K-Akt pathway was critical for the SDF-1-induced EMT.

\section{Discussion}

In this study, we investigated the EMT induced by the SDF-1/ CXCR4 system in oral SCC cells. The findings obtained from the present series of experiments were as follows. First, SDF-1 induced fibroblast-like morphological changes in CXCR4-expressing B88 and HNt cells. Second, the downregulation of epithelial markers and the upregulation of mesenchymal markers were also detected. Third, induction of mesenchymal marker, vimentin, and protruding extensions in the B88 cells with the treatment of SDF-1 was inhibited by treatment with PI3K inhibitor Wortmannin. These results suggest that the SDF-1/CXCR4 system induces EMT via activation of PI3K-Akt/PKB pathway.
Few common carcinoma cell types with a well-defined epithelial phenotype can complete EMT in vitro, perhaps because EMT is very sensitive to culture conditions, including substrates and the presence of serum (18). In the present study, oral SCC cells, both B88 and HNt cells changed morphology to a fibroblast phenotype by treatment with SDF-1; however, the alterations were dependent on culture conditions, i.e. serum starvation and low confluence. Although these reasons were unclear, factor(s) contained in the serum or molecule(s) recruited by a cell-cell tight contact might inhibit EMT by the SDF-1/CXCR4 system.

In the present study, both oral SCC cells, B88 and HNt, changed morphology to a fibroblast phenotype, which is associated with the alteration of EMT markers; however, the alterations are weak in $\mathrm{HNt}$ cells. HNt cells express functional CXCR4 (10), but the expression is 7.5-fold lower than that in B88 cells (12). Moreover, since HNt cells are somewhat heterogeneous, it might be considered that the expression of CXCR4 in each cell is different. Thus, in HNt cells, morphological changes associated with intracellular signaling by SDF-1 might be inadequate for the alteration of EMT markers. In contrast, Zhang et al reported that the autocrine HGF/cmet system was critical for the mesenchymal transition of mammary epithelial cells transformed by the expression of activated M-Ras (24). Therefore, B88 cells, but not $\mathrm{HNt}$ cells, might have critical pathway(s) for the enhancement of EMT.

Oral SCCs are characterized by a high degree of local invasiveness and a high rate of metastasis to the cervical lymph nodes. We have previously reported that oral SCC cells produce a large amount of matrix degrading enzyme, such as MMPs or uPAs (25), which might contribute to invasiveness and lymph node metastasis. During EMT, the involvement of MMPs or uPAs has been also suggested (26-28); however, we could not find significant alteration of MMP-2, MMP-7 and uPA by treatment with SDF-1. Scotton et al showed that the invasion of ovarian cancer cells through Matrigel stimulated by SDF-1 inhibited the presence of the MMP inhibitor, marimastat, but that no MMPs or tissue inhibitors of metalloproteinases (TIMPs) appeared to be regulated by SDF-1 (29). Therefore, they speculated that the ovarian cancer cells which they used produce a variety of matrixdegrading enzymes, and that SDF-1 merely gives them a direction in which to move. In the present study, B88 cells, which express several types of MMP (12), invaded the collagen gel, but could not form EMT change without treatment with SDF-1. Thus, MMPs or uPAs play a critical role in the invasion of oral SCC cells, but they might not contribute to the SDF-1induced EMT.

During EMT, epithelial cells acquire fibroblast-like properties and exhibit reduced cell-cell adhesion and increased motility. The plasticity afforded by EMT is central to the complex remodeling of embryo and organ architecture during gastrulation and organogenesis. In pathological processes such as oncogenesis, EMT may endow cancer cells with enhanced motility and invasiveness. Indeed, oncogenic transformation may be associated with signaling pathways promoting EMT (30), in which numerous studies have been conducted to investigate the ras-ERK or Akt/PKB pathways $(23,31,32)$. For example, Ellenrieder et al reported that TGF- $\beta 1$ 
treatment induced EMT in TGF- $\beta$-responsive pancreatic cancer cells with constitutive Ki-Ras mutations (31). Moreover, Grille et al demonstrated that oral SCC cell lines engineered to express constitutively active Akt underwent EMT, as characterized by the downregulation of the epithelial markers desmoplakin, E-cadherin, and ß-catenin, and by the upregulation of the mesenchymal marker vimentin (32). Chan et al reported that oncogenic ras and src, both inducers of EMT, also activate PI3K (33). Our group previously demonstrated that the src family kinases are involved in the SDF-1/CXCR4 mediated-lymph node metastasis in oral SCC (10). Thus, it is possible that the activation of the PI3K-Akt pathway via src family kinases might be involved in the establishment of EMT by the SDF-1/CXCR4 system.

We have previously reported the involvement of the SDF-1/ CXCR4 system in lymph node metastasis associated with oral squamous cell carcinoma (SCC) (10-12). During the process of lymph node metastasis, oral SCC cells must alter their morphology by use of EMT in order to intravasate into lymphatics through lymphatic valve (34). In the present study, oral SCC cells B88 and HNt were found to lose their epithelial cell morphology due to SDF-1, but the alterations could be recovered by the withdrawal of SDF-1. Thus, for the intravasation into lymphatics, oral SCC cells might use the SDF-1/CXCR4 system transiently to alter their shape as an 'EMT force'. When the cancer cells complete the intravasation into lymphatics, they might use the SDF-1/ CXCR4 system as an 'attractive force' for the establishment of lymph node metastasis. The expression of CXCR4 in oral SCC might be used as a molecular target of diagnosis, not only for lymph node metastatic potential, but also for EMT potential. Furthermore, CXCR4 inhibitors or antagonists might be potential anticancer agents to suppress both EMT and lymph node metastasis.

\section{Acknowledgments}

This study was supported in part by a grant-in-aid from the Ministry of Education, Science and Culture of Japan.

\section{References}

1. Rossi D and Zlotnik A: The biology of chemokines and their receptors. Annu Rev Immunol 18: 217-242, 2000.

2. Zlotnik A and Yoshie O: Chemokine a new classification system and their role in immunity. Immunity 12: 121-127, 2000.

3. Muller A, Homey B, Soto H, Ge N, Catron D, Buchanan ME, McClanahan T, Murphy E, Yuan W, Wagner SN, Barrera JL, Mohar A, Verastegul E and Zlotnik A: Involvement of chemokine receptors in breast cancer metastasis. Nature 410: 50-56, 2001.

4. Scotton CJ, Wilson JL, Milliken D, Stamp G and Balkwill FR: Epithelial cancer cell migration: a role for chemokine receptors? Cancer Res 61: 4961-4965, 2001.

5. Taichman RS, Cooper C, Keller ET, Pienta KJ, Taichman NS and McCauley LK: Use of the stromal cell-derived factor-1/ CXCR4 pathway in prostate cancer metastasis to bone. Cancer Res 62: 1832-1837, 2002.

6. Schrader AJ, Lechner O, Templin M, Dittmar KE, Machtens S, Mengel M, Probst-Kepper M, Franzke A, Wollensak W, Gatzlaff P, Atzpodien J, Buer J and Lauber J: CXCR4/CXCL12 expression and signalling in kidney cancer. Br J Cancer 86: 1250-1256, 2002.

7. Zhou Y, Larsen PH, Hao C and Yong VW: CXCR4 is a major chemokine receptor on glioma cells and mediates their survival. J Biol Chem 277: 49481-49487, 2002.
8. Kijima T, Maulik G, Ma PC, Tibaldi EV, Turner RE, Rollins B, Sattler M, Johnson BE and Salgia R: Regulation of cellular proliferation, cytoskeletal function, and signal transduction through CXCR4 and c-Kit in small cell lung cancer cells. Cancer Res 62: 6304-6311, 2002.

9. Hwang JH, Hwang JH, Chung HK, Kim DW, Hwang ES, Suh JM, Kim H, You KH, Kwon OY, Ro HK, Jo DY and Shong M: $\mathrm{CXC}$ chemokine receptor 4 expression and function in human anaplastic thyroid cancer cells. J Clin Endocrinol Metab 88: 408-416, 2003.

10. Uchida D, Begum NM, Ammar A, Nakashiro K, Kawamata H, Tateishi Y, Hamakawa H, Yoshida $H$ and Sato M: Possible role of stromal cell-derived factor-1/CXCR4 signaling on lymphnode metastasis of oral squamous cell carcinoma. Exp Cell Res 290: 289-302, 2003

11. Uchida D, Begum NM, Tomizuka Y, Bando T, Almofti A, Yoshida $\mathrm{H}$ and Sato M: Acquisition of lymph node, but not distant metastatic potentials, by the overexpression of CXCR4 in human oral squamous cell carcinoma. Lab Invest 84: 1538-1546, 2004.

12. Ammar A, Uchida D, Begum NM, Tomizuka Y, Iga H, Yoshida H and Sato M: The clinicopathological significance of the expression of CXCR4 protein in oral squamous cell carcinoma. Int J Oncol 25: 65-71, 2004.

13. Zeelenberg IS, Ruuls-Van Stalle L and Roos E: The chemokine receptor CXCR4 is required for outgrowth of colon carcinoma micrometastases. Cancer Res 63: 3833-3839, 2003.

14. Marchesi F, Monti P, Leone BE, Zerbi A, Vecchi A, Piemonti L, Mantovani A and Allavena P: Increased survival, proliferation, and migration in metastatic human pancreatic tumor cells expressing functional CXCR4. Cancer Res 64: 8420-8427, 2004.

15. Smith MC, Luker KE, Garbow JR, Prior JL, Jackson E, Piwnica-Worms D and Luker GD: CXCR4 regulates growth of both primary and metastatic breast cancer. Cancer Res 64: 8604-8612, 2004.

16. Guarino M: Epithelial-to-mesenchymal change of differentiation. From embryogenetic mechanism to pathological patterns. Histol Histopathol 10: 171-184, 1995.

17. Gilles C and Thompson EW: The epithelial to mesenchymal transition and metastatic progression in carcinoma. Breast $\mathrm{J} 2$ : 83-96, 1996.

18. Thiery JP: Epithelial-mesenchymal transitions in tumour progression. Nat Rev Cancer 2: 442-454, 2002.

19. Weidner KM, Sachs M and Birchmeier W: The Met receptor tyrosine kinase transduces motility, proliferation, and morphogenic signals of scatter factor/hepatocyte growth factor in epithelial cells. J Cell Biol 121: 145-154, 1993.

20. Zhu H, Naujokas MA and Park M: Receptor chimeras indicate that the Met tyrosine kinase mediates the motility and morphogenic responses of hepatocyte growth/scatter factor. Cell Growth Differ 5: 359-366, 1994.

21. Elliott BE, Hung WL, Boag AH and Tuck AB: The role of hepatocyte growth factor (scatter factor) in epithelial-mesenchymal transition and breast cancer. Can J Physiol Pharmacol 80: 91-102, 2002.

22. Janda E, Lehmann K, Killisch I, Jechlinger M, Herzig M, Downward J, Beug H and Grunert S: Ras and TGF-ß cooperatively regulate epithelial cell plasticity and metastasis: dissection of Ras signaling pathways. J Cell Biol 156: 299-313, 2002.

23. Xie L, Law BK, Chytil AM, Brown KA, Aakre ME and Moses HL: Activation of the Erk pathway is required for TGF-beta1-induced EMT in vitro. Neoplasia 6: 603-610, 2004.

24. Zhang KX, Ward KR and Schrader JW: Multiple aspects of the phenotype of mammary epithelial cells transformed by expression of activated M-Ras depend on an autocrine mechanism mediated by hepatocyte growth factor/scatter factor. Mol Cancer Res 2: 242-255, 2004.

25. Kawamata H, Nakashiro K, Uchida D, Hino S, Harada K, Yoshida $\mathrm{H}$ and Sato M: Possible contribution of active MMP2 to lymph-node metastasis and secreted cathepsin $\mathrm{L}$ to bone invasion of newly established human oral-squamous-cancer cell lines. Int J Cancer 70: 120-127, 1997.

26. Jorda M, Olmeda D, Vinyals A, Valero E, Cubillo E, Llorens A, Cano A and Fabra A: Upregulation of MMP-9 in MDCK epithelial cell line in response to expression of the Snail transcription factor. J Cell Sci 118: 3371-3385, 2005

27. Yokoyama K, Kamata N, Fujimoto R, Tsutsumi S, Tomonari M, Taki M, Hosokawa $\mathrm{H}$ and Nagayama $\mathrm{M}$ : Increased invasion and matrix metalloproteinase- 2 expression by Snail-induced mesenchymal transition in squamous cell carcinomas. Int $\mathbf{J}$ Oncol 22: 891-898, 2003. 
28. Gilles C, Polette M, Birembaut P, Brunner N and Thompson EW: Expression of c-ets-1 mRNA is associated with an invasive, EMT-derived phenotype in breast carcinoma cell lines. Clin Exp Metastasis 15: 519-526, 1997.

29. Scotton CJ, Wilson JL, Scott K, Stamp G, Wilbanks GD, Fricker S, Bridger G and Balkwill FR: Multiple actions of the chemokine CXCL12 on epithelial tumor cells in human ovarian cancer. Cancer Res 62: 5930-5938, 2002.

30. Boyer B, Valles AM and Edme N: Induction and regulation of epithelial-mesenchymal transitions. Biochem Pharmacol 60: 1091-1099, 2000.

31. Ellenrieder V, Hendler SF, Boeck W, Seufferlein T, Menke A, Ruhland C, Adler G and Gress TM: Transforming growth factor beta1 treatment leads to an epithelial-mesenchymal transdifferentiation of pancreatic cancer cells requiring extracellular signal-regulated kinase 2 activation. Cancer Res 61: 4222-4228, 2001.
32. Grille SJ, Bellacosa A, Upson J, Klein-Szanto AJ, van Roy F, Lee-Kwon W, Donowitz M, Tsichlis PN and Larue L: The protein kinase Akt induces epithelial mesenchymal transition and promotes enhanced motility and invasiveness of squamous cell carcinoma lines. Cancer Res 63: 2172-2178, 2003.

33. Chan TO, Rodeck U, Chan AM, Kimmelman AC, Rittenhouse SE, Panayotou G and Tsichlis PN: Small GTPases and tyrosine kinases coregulate a molecular switch in the phosphoinositide 3kinase regulatory subunit. Cancer Cell 1: 181-191, 2002.

34. Kawamata H, Uchida D, Nakashiro K, Omotehara F, Hino S, Yoshida $\mathrm{H}$ and Sato $\mathrm{M}$ : Invasion and metastasis of oral cancer. Recent Res Devel Cancer 1: 37-46, 1999. 